\title{
Danish heat atlas as a support tool for energy system models
}

\author{
Petrovic, Stefan; Karlsson, Kenneth Bernard
}

Published in:

Energy Conversion and Management

Link to article, DOI:

10.1016/j.enconman.2014.04.084

Publication date:

2014

Document Version

Peer reviewed version

Link back to DTU Orbit

Citation (APA):

Petrovic, S., \& Karlsson, K. B. (2014). Danish heat atlas as a support tool for energy system models. Energy Conversion and Management, 87, 1063-1076. https://doi.org/10.1016/j.enconman.2014.04.084

\section{General rights}

Copyright and moral rights for the publications made accessible in the public portal are retained by the authors and/or other copyright owners and it is a condition of accessing publications that users recognise and abide by the legal requirements associated with these rights.

- Users may download and print one copy of any publication from the public portal for the purpose of private study or research.

- You may not further distribute the material or use it for any profit-making activity or commercial gain

- You may freely distribute the URL identifying the publication in the public portal

If you believe that this document breaches copyright please contact us providing details, and we will remove access to the work immediately and investigate your claim. 


\title{
Danish heat atlas as a support tool for energy system models
}

\author{
Stefan N. Petrovic ${ }^{*}$, Kenneth B. Karlsson \\ Department of Management Engineering, Technical University of Denmark, \\ Frederiksborgvej 399, Building 130, 4000 Roskilde, Denmark
}

\begin{abstract}
In the past four decades following the global oil crisis in 1973, Denmark has implemented remarkable changes in its energy sector, mainly due to the energy conservation measures on the demand side and the energy efficiency improvements on the supply side. Nowadays, the capital intensive infrastructure investments, such as the expansion of district heating networks and the introduction of significant heat saving measures require highly detailed decision support tool. A Danish heat atlas provides highly detailed database with extensive information about more than 2.5 million buildings in Denmark. Energy system analysis tools incorporate environmental, economic, energy and engineering analysis of future energy systems and are considered crucial for the quantitative assessment of transitional scenarios towards future milestones, such as EU 2020 goals and Denmark's goal of achieving fossil free society after 2050. The present paper shows how a Danish heat atlas can be used for providing inputs to energy system models, especially related to the analysis of heat saving measures within building stock and expansion of district heating networks. As a result, marginal cost curves are created, approximated and prepared for the use in optimization energy system model. Moreover, it is concluded that heat atlas can contribute as a tool for data storage and visualization of results.
\end{abstract}

\section{KEYWORDS}

energy system models; GIS; heat savings; district heating; heat atlas; demand and supply

* Corresponding author, Tel.: +45-2465-5732.

E-mail addresses: stpet@dtu.dk (S. Petrovic), keka@dtu.dk (K. Karlsson). 


\section{Introduction}

Before 1973, the time of first oil crises, Denmark was totally dependent on the imported oil, with oil making for 92 percentages of the total primary energy consumption. Almost entire transportation sector and residential heating was oil-based, while share of oil in electricity production was 78 percentages; the rest of electricity production was based on coal [1]. Sudden rise in oil prices forced Danish authorities to pursue different energy planning strategies than just building new production, transmission and distribution facilities and thus serving consumption that was increasing from year to year.

Denmark drastically changed appearance of its energy system during past decades - total primary energy supply remained unchanged while total energy used for heating buildings was reduced by $26 \%$. In the same time period, total heated area grew up for more than $50 \%$ [2]. This is done by constantly improving energy efficiency and introducing energy saving measures. Wall [3] identified analogous strategy for designing energy systems as the proper direction towards sustainable society, while [4] found that energy conservation is crucial for reducing harmful environmental impacts. Energy efficiency was mainly affected by introducing large number of CHPs (Combined Heat and Power) in the system, technologies which are using waste heat from electricity production as a heating source for residential buildings or industrial processes. Energy savings in buildings were achieved by using materials with smaller heat conductivity in the buildings' envelopes. Along with reduction in the primary energy consumption and fighting the issue of resource depletion, energy savings and efficiency measures have decreased harmful environmental impact of energy systems. Also, use of oil for covering heat demand is reduced from more than $90 \%$ in 1972 to about $10 \%$ in 2011 , thus improving security of energy supply and making complete energy system less prone to changes in oil prices.

The environmental impact of improved energy efficiency is even more evident when considering the current Danish heating system: $52 \%$ of the total net heat demand in Denmark is covered by district heating, of which $76 \%$ is produced in the CHPs [1]. One third of energy produced in CHP processes in 2007 was based on renewable energy [6] - this fact shows how the environmental impact is reduced by the use of CHPs and district heating technologies. Lund and Andersen [7] observed that CHP-based district heating is essential for implementation of climate change response objectives in many countries. Similarly, positive global environmental effects have been observed in [8]. In line with this, in 2008, Denmark, as one of EU members adopted long term targets in the area of renewable energy and energy efficiency: 1) $20 \%$ reduction in emission of greenhouse gasses by 2020 compared with 1990, 
2) by $2020,20 \%$ of final energy demand should be covered by renewable energy, such as wind, solar and geothermal energy and 3) $20 \%$ reduction in total energy consumption by improving energy efficiency in the whole chain production-transmission-distribution-end-use compared to business-as-usual scenario. Denmark went even further with the renewable energy targets, setting the 2020 goal for share of renewable energy in final energy consumption to $30 \%$ [9].

Although it is possible to see energy from many different sides, such as environmental, technical, technological, economical or behavioural, every segment of energy flow from the production to the end-use is spatially distributed and thus geographical in nature. Energy plants can be described by its efficiency, type and amount of fuel used, maximum output and many more and put into the spatial context by assigning spatial coordinates. The same stands for other elements of energy systems, such as sources of energy, transmission and distribution facilities and consumers, such as households and industry - unique spatial coordinates could be assigned to all these elements. Aydin et al. [10] have addressed the lack of solar and wind resources at all geographical locations and proposed GIS based site-selection method for positioning of hybrid wind-PV systems. Spatial nature of energy systems is especially underlined in the case of changes in the collective heat supply, such as expansion of district heating or the implementation of significant heat saving measures. Then, answers to spatial related questions, such as 'Where are the existing $\mathrm{DH}^{1}$ areas?', 'How far away are these houses from the existing DH areas?' or 'What is the heat density inside this area?' represent starting point in energy system analysis. Finney et al. [11] have answered all these questions about the DH network in Sheffield before analysing economic and environmental consequences of expanding DH in [12].

Spatial aspect of energy planning played an important role in the transition of Denmark's energy system from polluting and inefficient imported-oil-based to modern, efficient energy system primarily based on renewable energy, CHPs and district heating. The first major policy statement was published in 1976 by Ministry of Trade and it has declared aims for Danish energy policy. The energy efficiency was addressed by the use of CHPs and district heating, energy savings by improving insulation on buildings, while dependency on imported fuels was addressed by switching to use of coal, renewable energy, natural gas and nuclear power. The ideas about using nuclear power were abandoned later. Heat Supply Act, passed in 1979 , required that communes, in cooperation with regional public utility companies, map

\footnotetext{
${ }^{1}$ If not stated otherwise, acronym DH is used for district heating throughout the paper.
} 
present and future energy needs at the local level on the basis of small heat districts, the so called energy districts. A national, geo-based system for energy planning was created information about number of houses supplied by different fuels and supply technologies was easily accessible. Then, on the basis of energy districts, counties drew up their own heat supply plans, which had to contain fuels that will be prioritised in the future, locations of future investment in collective heating and locations of specific activities that are producing or consuming large quantities of heat. For the newly developed areas, a collective heat supply was prescribed. Later, each commune had to draw up own heating plan in agreement with the counties' heating plan [13]. Creation of heat plans and delineation of energy districts denoted beginning of regional energy planning. In the same time, due to geographical nature of energy districts, same process could be interpreted as a first use of spatial decision support tool, a heat atlas. In 1970's and 1980's heat atlases were based on hand drawn paper maps, while in 1990's they started being incorporated in computerised GIS software. Today, heat atlas can be seen as highly precise, data-intensive decision support tool that provides huge possibilities for data storage, analysis and visualisation.

The current paper investigates how Danish heat atlas can be used as a support tool for energy system models. It is shown how detailed data from heat atlas together with GIS tools can be used to create cumulative cost curves for DH expansion and heat savings in building stock. Later, these curves have been approximated and prepared for the use in the TIMES model for Denmark. Finally, use of GIS based heat atlas for representing results from energy system models has been discussed.

\section{Methodology}

\subsection{Danish heat atlas}

If not specified otherwise, current paper tends to describe use of a heat atlas developed at Aalborg University and presented in [5]. It is designed as File Geodatabase in ESRI's ArcGIS 10 software. This software has been chosen, because it is capable of efficiently storing and operating huge datasets and it offers variety of analytical tools and good connectivity.

A heat atlas contains spatially referenced data for about 2.5 million buildings in Denmark. Each building is represented as single point within GIS software. Heat supply data include heat installations (individual boilers, electric heating, district heating, etc.), fuel used in individual heating (natural gas, wood chips, straw, etc.) and means of supplementary heating. 
Non-energy related data, such as construction year and building type, heated area, conservation status, region, address, commune, postal and parish code, etc. are also included in a heat atlas and comprise a sound basis for computation of specific building parameters using empirical formulas. Further socio-economic parameters, such as levels of income or education, property values, number of inhabitants or similar could be included in the future [5]. Even when taking privacy issues into account, these data are publicly available with high resolution. With all-time progress of computer hardware and GIS software, storing and operating huge amounts of data doesn't seem to be a problem either, but problem seems to be on empirical side. Heated area of buildings, age and type accompanied with empirical data about specific heat losses and DHW ${ }^{2}$ consumption were used in a spread sheet model developed by Wittchen [14] to calculate net heat demand for total of 175 types of residential buildings. Another approach, developed by Næeraa and Karlsson [15] was used for calculating net heat demands in commercial and public buildings. Net heat demand calculated in Heat Atlas was adjusted to Danish Energy Statistics data [1] and validated in study Heat Plan for Denmark [16]. It surely isn't the matter of coincidence that GIS based heat atlas of such high detail was created for Denmark. Denmark has a relatively small population of around 5.5 million and about 2.5 million buildings. In the same time, highly developed statistical office (Statistics Denmark) keeps track on people's residence, age, income, education and employment while national register of buildings and dwellings (BBR) maintains records about physical properties of buildings, construction year, area and many more. Thus, publicly kept registers with high level of detail, containing data specified by geography, along with big experience in using heat supply plans, comprise a solid fundament for creation of GIS based decision-support tool - a heat atlas.

\subsection{GIS based heat atlas for calculations of district heating expansion and heat savings}

Heat atlas was used in [17] to recalculate heat demand for DHW and space heating and assess potentials and costs of different heat saving measures for 360 types of buildings. GIS based heat atlas was also used as a basis for calculation of potentials and costs of DH expansion. These results were used as inputs to optimization energy system model TIMES for Denmark.

\footnotetext{
${ }^{2}$ Acronym DHW is used for domestic hot water throughout the paper.
} 


\subsubsection{Relation between heat savings and DH expansion}

The idea behind heat atlas, process of creation and applicability of heat atlas are described in [5]. The analysis of heat saving measures and expansion of district heating networks were underlined as the two main fields for which this model can provide a sound information base. Especially, a heat atlas can be used for the data storage and the analysis of heat saving measures in areas with $\mathrm{CO}_{2}$ intensive energy sources and for the analysis of advanced heating technologies inside DH areas. Contrary to the opinions that heat savings will reduce competiveness of district heating, there are multiple studies claiming that energy savings in buildings and industry, expansion of district heating in energy dense areas, introduction of $4^{\text {th }}$ generation of district heating with lower supply and return temperatures and use of heat pumps in the individual areas represent optimal path towards renewable and sustainable energy targets. In the following studies, heat atlas methodology is used for analysing technical, environmental and economic impact of heat savings and district heating expansion. Möller and Lund [6] conclude that it is socio - economically feasible to expand district heating to somewhere in between $50 \%$ and $70 \%$, mostly within energy dense areas such as towns and cities, and thus reduce $\mathrm{CO}_{2}$ emissions and fuel consumption. The scenarios with and without reduction in energy consumption in buildings were examined. Persson and Werner [18] have calculated district heating distribution capital costs for European cities of various characteristics, sizes and heat demands and concluded that district heating can be expanded up to $60 \%$ at relatively low socio - economic costs. They also find that the most suitable conditions for district heating are within large cities and in inner city areas. However, they claim that district heating will lose competiveness in low heat density areas. Although heat atlas for Denmark isn't directly used in this paper, heat atlas methodology is applied. Lund at al. [19] describe district heating as technology that should be gradually expanded and accompanied by heat pumps in low energy density areas, today as well as in future $100 \%$ renewable energy systems. Hedegaard and Münster [20] have also found heat pumps as a favourable heat supply solution for low heat density areas. Sperling and Möller [21] have investigated short term ("transitional") energy scenarios for local energy system of Frederikshavn, where they assumed shares of district heating up to $92 \%$, while in the same time investing in heat savings. In this study, data about building stock contained in heat atlas were adjusted to match local conditions. This was done by adjusting heat demand for normal degree days for Northern Denmark, comparing fuel types used for heating with local utility company and natural gas provider and comparing type of heat installation with local chimney 
sweeper data. Nielsen and Möller [22] went even one step further in describing future relation between district heating systems and heat savings in building stock by exploring NZEBs, buildings with small annual consumption of around $33 \mathrm{kWh} / \mathrm{m}^{2}$ and similar amount of energy produced during summer months. They have concluded that NZEBs can benefit DH systems by substituting for the production from combustible fuels, especially after adding seasonal heat storage in areas where excess heat from renewable sources is produced during summer months.

Tommerup and Svendsen [23] have analysed heat saving potential within residential building stock in Denmark. They have calculated that $80 \%$ of current energy demand for space heating and domestic hot water can be reduced before 2050, only if profitable heat savings are taken into account. Petrovic and Karlsson [17] have used Danish heat atlas in their calculations and have concluded that heat demand in Danish building stock can be reduced between 75 and $85 \%$, depending on whether the renovations are undertaken as scheduled or energy-saving renovations.

\subsubsection{Calculation of costs of DH expansion}

District heating is seen as very popular type of heating in Denmark and was covering $48 \%$ of final energy consumption for space heating in 2011. Most of the heat is produced in cogeneration plants, mainly from renewably sources, which significantly reduce environmental effects of heat production while improving overall efficiency. Main advantages of district heating in future Danish energy system that will be totally based on renewables are:

- Possibility of using waste heat and work together with heat pumps and heat storages to utilise excess electricity production from wind power. Wind power is expected to play major role in Danish energy system, as $50 \%$ of electricity needs should be produced from wind power by year 2020. This way district heating systems will add flexibility to the energy system.

- Capability of utilising waste heat from various sources, such as industrial and waste incineration facilities and CHP plants. Also, when coal and oil fired power plants switch to biogas and biomass, district heating systems will continue to utilise waste heat without need for expensive mechanical alterations.

Main disadvantages of district heating will be overcome on the road towards completely renewable energy system: 
- The high investment costs will be partially compensated by using waste energy from various processes which is free of charge. The high initial costs of district heating alternative will also be reduced by avoiding investments in individual heating equipment.

- Significant heat losses will be reduced by switching to low-temperature district heating with supply temperatures of around $55^{\circ} \mathrm{C}$ and return temperatures of $35^{\circ} \mathrm{C}$, along with reducing space heating demand.

If technical potential for expanding district heating is considered, it is possible to cover 100 $\%$ of heat demand with district heating. Economically feasible potential is lower, even when it is seen from socio-economic point of view. When the private-economic perspective is applied, economic feasibility might be further reduced. As mentioned earlier, after looking from the socio - economic perspective, it is found that DH has potential of covering 55 [24] to $70 \%$ [19] on national scale and even up to $92 \%$ on local scale [21].

The costs of expanding are seen as deciding parameter for separating socio-economic from technical potential for expanding existing DH networks. As such, these costs are of major importance for the current and the future energy system. The procedure for calculating costs of DH expansion is described below. Heat atlas methodology was applied and appropriate GIS analysis tools available in ArcGIS 10.1 were used. Costs of connecting all buildings within district heating (DH) areas, Next-to-DH and Individual areas with individual heat supply to DH networks have been calculated by using the following procedure:

1. Layer containing boundaries of cities and towns is imported into ArcGIS software.

2. Buildings that are connected to DH networks are grouped into polygons, called DH areas. Buildings that are not connected to DH systems and are not located within DH areas but are geographically located within cities or towns are grouped into polygons called Next-to-DH areas. Buildings that are not connected to DH systems and aren't located within boundaries of cities are grouped into polygons called Individual areas.

3. Each DH and each Individual area had position of their centroid calculated. The distances from centroids of Individual areas to centroids of nearest DH areas were measured. Distances from Individual to DH areas represent decisive parameter that determines costs transmission infrastructure. In this step, Individual areas were aggregated based on total calculated demand for space heating and DHW and 
placed into 9 groups. The different value for specific costs of transmission infrastructure (in millions of $\mathrm{DKK}^{3}$ per $\mathrm{km}$ ) was assigned to each group.

4. Areas (in $\mathrm{km}^{2}$ ) of previously created Individual and Next-to-DH areas (polygons) were measured within GIS software. After that, specific costs of distribution infrastructure (in millions of DKK per $\mathrm{km}^{2}$ ) were assigned to each of these areas.

5. All buildings spatially located within 3 types of areas are grouped into 3 groups (Small, Medium and Large buildings) based on their calculated annual heat demand (in MWh annually). Buildings within each group were counted and costs of connecting pipes and heat exchangers were assigned to each group of buildings.

6. The investment costs of connecting certain area to existing district heating infrastructure were calculated using following expression:

$C=C_{T R}+C_{D I S T}+C_{C O N N}=c_{T R} \cdot d_{D H-I N D}+c_{D I S T} \cdot A+$
$+\left(c_{C O N N, s}+c_{H E, s}\right) \cdot n_{s}+\left(c_{C O N N, m}+c_{H E, m}\right) \cdot n_{m}+\left(c_{C O N N, l}+c_{H E, l}\right) \cdot n_{l}$

where used symbols have following meaning:

$\mathrm{C}$ - Total investment costs of connecting one area to existing DH system. In case of DH areas these are the costs of switching all buildings inside $\mathrm{DH}$ area to district heating.

$\mathrm{C}_{\mathrm{TR}}, \mathrm{C}_{\mathrm{DIST}}, \mathrm{C}_{\mathrm{CONN}}-$ Costs of transmission, distribution and connection infrastructure for all the buildings in a specific area within 3 groups of areas, respectively.

$c_{T R}$ - Specific costs of district heating transmission infrastructure in $\frac{\text { mill } D K K}{\mathrm{~km}} . c_{T R}$ depends on heat demand that is supplied by a specific transmission line.

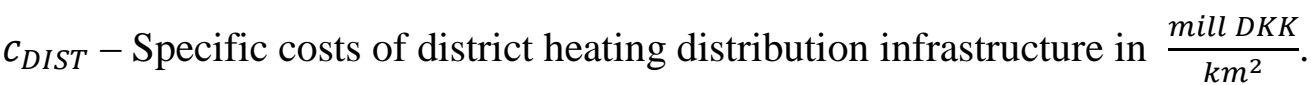

A - Area of a specific Next-to-DH or Individual area in $\mathrm{km}^{2}$,

$c_{C O N N, S}, c_{H E, S}, c_{C O N N, m}, c_{H E, m}, c_{C O N N, l}, c_{H E, l}-$ costs of connecting pipes and heat exchangers

for Small, Medium and Large buildings in $10^{3} \frac{D K K}{\text { building }}$, respectively. Buildings were regarded as a Small if their annual heat demand is below $50 \mathrm{MWh}$, Medium if annual heat demand was between 50 and 350 MWh and Large if their annual heat demand for DHW and space heating was exceeding $350 \mathrm{MWh}$.

\footnotetext{
${ }^{3}$ DKK represents Danish crown. Exchange rate with EUR is almost fixed and amounts to 1 EUR=7.45 DKK.
} 
$\mathrm{d}_{\text {DH-IND }}$ - Straight-line distance between centroid of one Individual area and the nearest centroid of one district heating area.

$n_{s}, n_{m}, n_{l}$ - Number of small, medium and large buildings within one geographical area.

As can be seen from expression (1), grouping of areas by their position relative to previously defined DH areas on DH, Next-to-DH and Individual areas reflect physical and economical nature of district heating expansion:

- In order to expand DH to buildings within DH areas, investments in connecting pipes and heat exchangers must be made, as transmission and distribution infrastructure already exists in these areas.

- Expansion of DH into Next-to-DH areas, which are sharing a border with DH areas, needs to be accompanied with the investments in the distribution and the connection infrastructure, including the heat exchangers. It is assumed that a transmission infrastructure already exists in the close vicinity of Next-to-DH areas and that these investments are not needed.

- Investment costs for expanding DH into Individual areas are composed of costs for transmission, distribution and connection infrastructure and heat exchangers, since there is no existing infrastructure that could be used to supply these areas with district heat.

\subsubsection{Heat savings in existing building stock}

As mentioned, Denmark successfully followed the road from dependency on imported oil towards self-sufficiency in terms of energy supply by following two main directions: energy savings and efficiency improvements. The energy savings were mainly addressed by reducing energy demand in building environment. In 2011, gross heat consumption for space heating amounted to around $202 \mathrm{PJ}$, which corresponds to approximately one third of the final energy consumption in Denmark in the same year. Despite significant heat demand reductions through successful energy saving policies and regulations, this amount of energy still represents large part of total demand and thus a potential for demand reduction measures. Net

25 zero energy buildings with total heat demand of around $33 \frac{\mathrm{kWh}}{\mathrm{m}^{2}}$ of heated area (with domestic hot water making more than half of demand), described in [22] could serve as indicator how far is it possible to go with heat savings. The aim of this section is to show how 
a heat atlas accompanied with physical model of building's thermal characteristics essentially based on [25] and thoroughly elaborated in [17] can be used for answering questions such as "How big are heat losses in specific building?", "How much energy can be saved by replacing windows in specific area?", or "How much would it costs to save specific amount of energy within certain area in East Denmark?".

Heat demand in a single building ${ }^{4}$, which represents the smallest entity contained in Heat Atlas, can be described by following equation:

$H_{\text {dem }}=H_{\text {env }}+H_{\text {ven }}+H_{\text {dhw }}-H_{\text {sol }}-H_{\text {int }}$,

where used symbols have following meaning:

$H_{d e m}$ - Total demand for heat inside single building that should be covered by a heat source.

$H_{\text {env }}$ - Heat loss through different elements of a building envelope, such as windows, walls, floors and roofs.

$H_{\text {ven }}$ - Heat losses caused by ventilation.

$H_{d h w}$ - Heat demand needed for domestic hot water preparation.

$H_{\text {sol }}$ - Solar heat gains caused by solar radiation entering through windows.

$H_{\text {int }}$ - Internal heat gains as a result of waste heat produced by electrical appliances and heat produced by human bodies.

$H_{e n v}$ is a consequence of building elements' property to transfer heat from warmer to colder place and is directly proportional to heat transfer coefficient ( $\mathrm{u}$ values), temperature difference between warmer and colder place and the size of the transmitting surface. It is assumed that heat savings or reduction of heat losses through different elements of building's envelope are achieved by replacing building's elements with elements with lower u-values, as can be seen from the following equation:

$S A V_{\text {env }}=\sum_{m} \sum_{\text {elem }}\left(u_{\text {elem }}{ }^{\text {old }}-u_{\text {elem }}{ }^{\text {new }}\right) \cdot A \cdot f_{\text {elem }} \cdot\left(t^{\text {ind }}-t_{m}^{\text {out }}\right) \cdot d_{m} \cdot k_{24} \cdot k_{\text {elem }}{ }^{t}$

where used symbols have the following meaning:

$\mathrm{m}-$ Months of year.

\footnotetext{
${ }^{4}$ For the detailed description of the model used for calculating the heat demands, heat saving potentials and associated costs, the reader should consult ref. [17].
} 
elem - elements of building envelope: walls, floors, windows, roofs.

$u_{\text {elem }}{ }^{\text {old }}, u_{\text {elem }}{ }^{\text {new }}$ - heat transfer coefficient of specific building's envelope elements before and after the renovation (in $\frac{W}{m^{2} \cdot K}$ )

$A$ - Heated area of a building (in $\mathrm{m}^{2}$ ), obtained from heat atlas.

$f_{\text {elem }}=\frac{A_{\text {elem }}}{A}-$ Coefficient that relates area of specific element of building's envelope with heated area of building [26].

$t^{\text {ind }}$ - Indoor temperature, based on [27].

$t_{m}^{\text {out }}$ - Outdoor temperature in month $\mathrm{m} . t_{m}^{\text {out }}$ is separately defined for 8 different regions in Denmark, as specified in [28].

$d_{m}$ - Number of heated days in month m, obtained from [29].

$k_{24}=0.024-$ Constant used as multiplier with 24 (hours in one day) and divider by 1000 (Wh in one $\mathrm{kWh}$ ).

$k_{\text {elem }}{ }^{t}$ - Correction factor that takes into account that floor is conducting heat to area with temperature greater than $t_{m}^{\text {out }}$ [30].

Equation (3) has a slightly different form in case of windows, because effects of change in glass area relative to window area and change in transmittance are also taken into account. Due to reasons of simplicity, this effect hasn't been presented.

$H_{v e n}$ is a result of natural ventilation or mechanical ventilation without heat recovery. In that case, efficiency of heat recovery, $\eta_{\text {old }}=0$. It is assumed that reduction of ventilation heat losses are achieved by installing ventilation systems with heat recovery that have efficiency of heat recovery of $\eta_{\text {new }}=0.9$ :

$S A V_{\text {vent }}=\sum_{m} \mathrm{\eta}_{\text {new }} \cdot 0.34 \cdot n \cdot H \cdot A \cdot\left(t^{\text {ind }}-t_{m}^{\text {out }}\right) \cdot d_{m} \cdot k_{24}$

where $n\left(h^{-1}\right)$ represents air exchange rate and $\mathrm{H}(\mathrm{m})$ represents average room height. Exact numerical values for $\mathrm{n}$ and $\mathrm{H}$ are obtained from [27].

$\mathrm{H}_{\mathrm{dhw}}$ is the domestic hot water consumption and it is a result of consumers' need for hot water and heat losses within buildings. Heat savings related to consumers' behaviour haven't been explored, but heat losses from installations located inside the buildings could be lowered by insulating hot water pipes, as can be seen from equation (5):

$S A V_{d h w}=\frac{p}{100} \cdot l \cdot A \cdot q_{d h w, s a v}$, 
where $\mathrm{p}(\%)$ is a percentage of domestic hot water pipes within one building being insulated, 1 is average the length of hot water pipes per heated area of building, A is the heated area of specific building and $q_{d h w, s a v}$ represents energy savings per $\mathrm{m}$ of insulated pipes. Numerical values for 1 have been obtained from [31] and for $q_{d h w, s a v}$ from [21]. It has been calculated that reduction in energy demand for preparing domestic hot water coming from insulation of hot water pipes doesn't exceed $5 \%$ of the hot water demand.

When heat savings are accomplished, reductions in heat demand and accordingly reductions in heat supply occur within the energy system. For each heat saving measures additional and full costs per $\mathrm{m}^{2}$ of building element are used for the different levels of heat savings. The costs for insulating DHW pipes are obtained from [30], for walls, roofs and floors from [27], while costs of windows and mechanical ventilation systems are obtained from [32]. In total, 13 different levels of heat savings are assumed - three for improving insulation on roofs, walls and windows, one for insulating floors and installing ventilation systems with heat recovery and two levels for insulating hot water pipes. Additional costs are used if heat savings are implemented when buildings are subjected to scheduled renovation and reflect only additional expenses of heat saving measures. In case of building's renovation is done solely with an aim of saving energy, full costs are considered. The calculated costs are annualised with $4 \%$ socio-economic interest rate over lifetimes of buildings' elements- 40 years for walls, floors and roofs, 30 years ventilation systems and 20 years for windows and DHW pipes. The lifetimes for walls, ventilation systems and DHW pipes are obtained from [30], while lifetimes of roofs, floors and windows are obtained from [32]. Ventilation systems have also O\&M costs assigned.

\section{Results}

\subsection{Marginal costs of expansion of $\mathrm{DH}$ networks}

The investment costs of expanding DH are calculated for all DH, Next-to-DH and Individual areas and presented in Figure 1. Costs were discounted with $4 \%$ interest rate as recommended in [33] over 40 year period, as recommended in [34]. It can be observed from Figure 1 that the highest socio-economic potential for $\mathrm{DH}$ expansion lies within already existing DH areas, usually towns or cities, where transmission and distribution infrastructure already exists. It is more expensive to expand district heating into the neighbouring areas, as distribution infrastructure is needed. These areas have highest technical potential, but big part 
of that potential comes with annualized discounted price greater than $0.1 \mathrm{DKK} / \mathrm{kWh}$, the price needed to connect $95 \%$ of all $\mathrm{DH}$ areas. Parts of technical potential were omitted from the figure 1 in order to make all curves fit the same scale. The buildings within the Individual areas have high technical but low socio - economic potential, due to high investment costs of the transmission infrastructure. It is most likely that these areas will remain supplied by individual means of heating and this is where heat pumps as efficient and environmentally friendly source of heating could prove to be very effective, especially when taking increasing amounts of wind energy in Danish energy system into account.

In order to underline the fact that all parts of the curves presented in the Figure 1 have their spatial origin and thus highlight level of detail provided by a heat atlas, red arrow is pointed at the part of the curve that represents Vindinge Individual area, located near Roskilde in Central Sealand. The data about buildings located in this area are provided in Table 1. The way how distances between centroids and areas of polygons are measured in ArcGIS software is presented in Figure 2, for the case of Roskilde DH area and Vindinge Individual area.

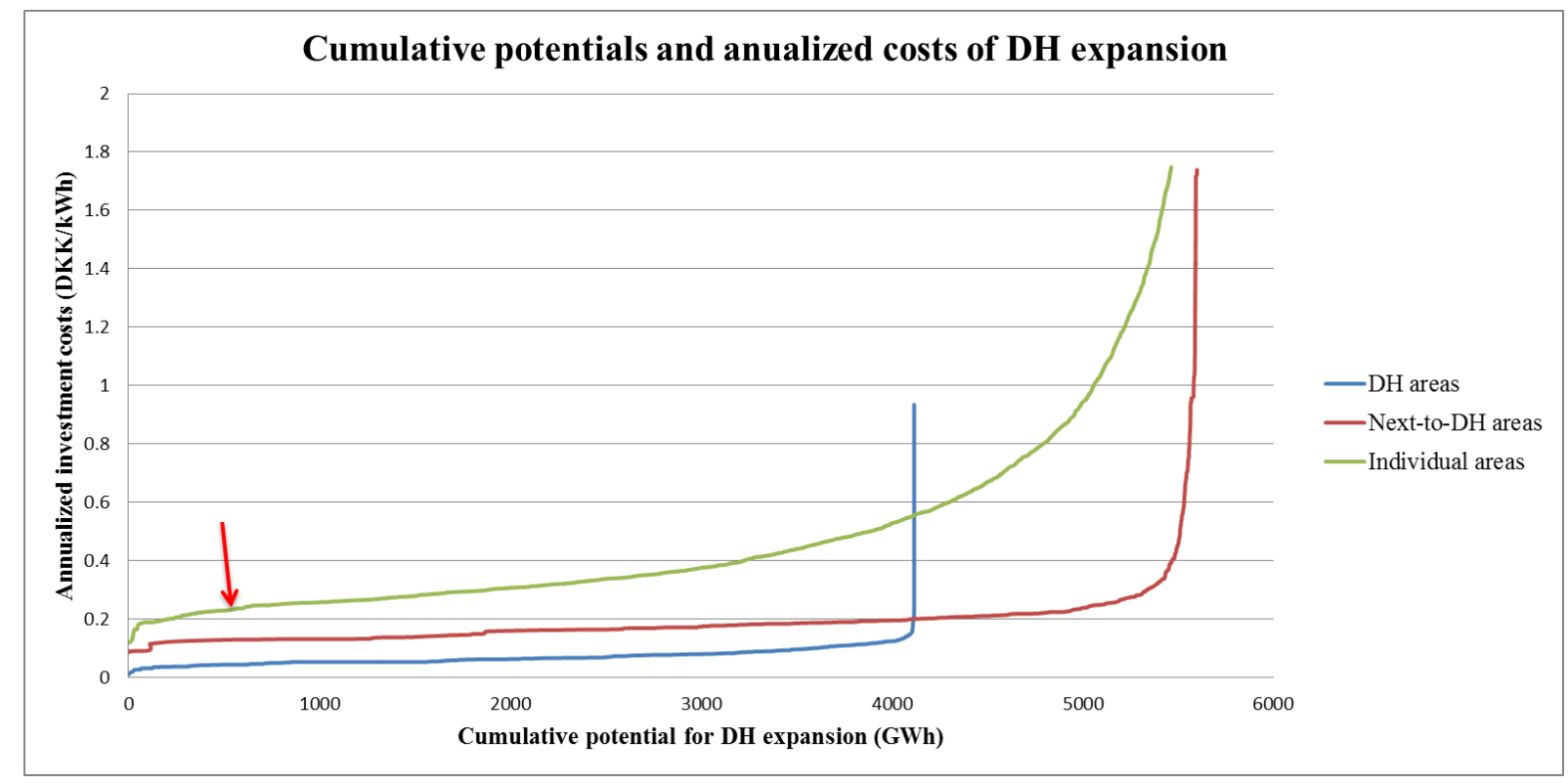

Figure 1. Cumulative potential for expansion of district heating and associated annualized investment costs. 
Table 1. Number and characteristics of buildings in Vindinge Individual heating area.

\begin{tabular}{lcccc}
\hline \multicolumn{1}{c}{ Size } & $\begin{array}{c}\text { Range } \\
\left(\frac{\boldsymbol{M} \boldsymbol{W h}}{\boldsymbol{y e a r}}\right)\end{array}$ & $\begin{array}{c}\text { Number of } \\
\text { buildings }\end{array}$ & $\begin{array}{c}\text { Total heated area } \\
\left(1000 \mathrm{~m}^{2}\right)\end{array}$ & $\begin{array}{c}\text { Total heat demand } \\
(\mathrm{GWh})\end{array}$ \\
\hline Large & $0-50$ & 0 & 0 & 0 \\
\hline Medium & $50-350$ & 6 & 7.9 & 1.02 \\
\hline Small & $>350$ & 687 & 100.3 & 11.52 \\
\hline
\end{tabular}

High level of details provided by a heat atlas has already been used for examining socioeconomic feasibility of expanding DH in previous studies $[6,20,24]$. The difference in the approach presented in this paper is that $\mathrm{DH}$ areas, which have the highest potential to be fully converted to district heating, are formed within GIS software and haven't been taken from administrative databases. Using administratively created DH areas could be a potential source of two types of errors: 1 . Administrative databases could be outdated, meaning that DH has already been expanded to certain areas, but the expansion wasn't recorded in the heat supply plans and 2. Administrative databases could contain areas designated as the future DH areas, but it is possible that DH was never physically expanded to that region. 


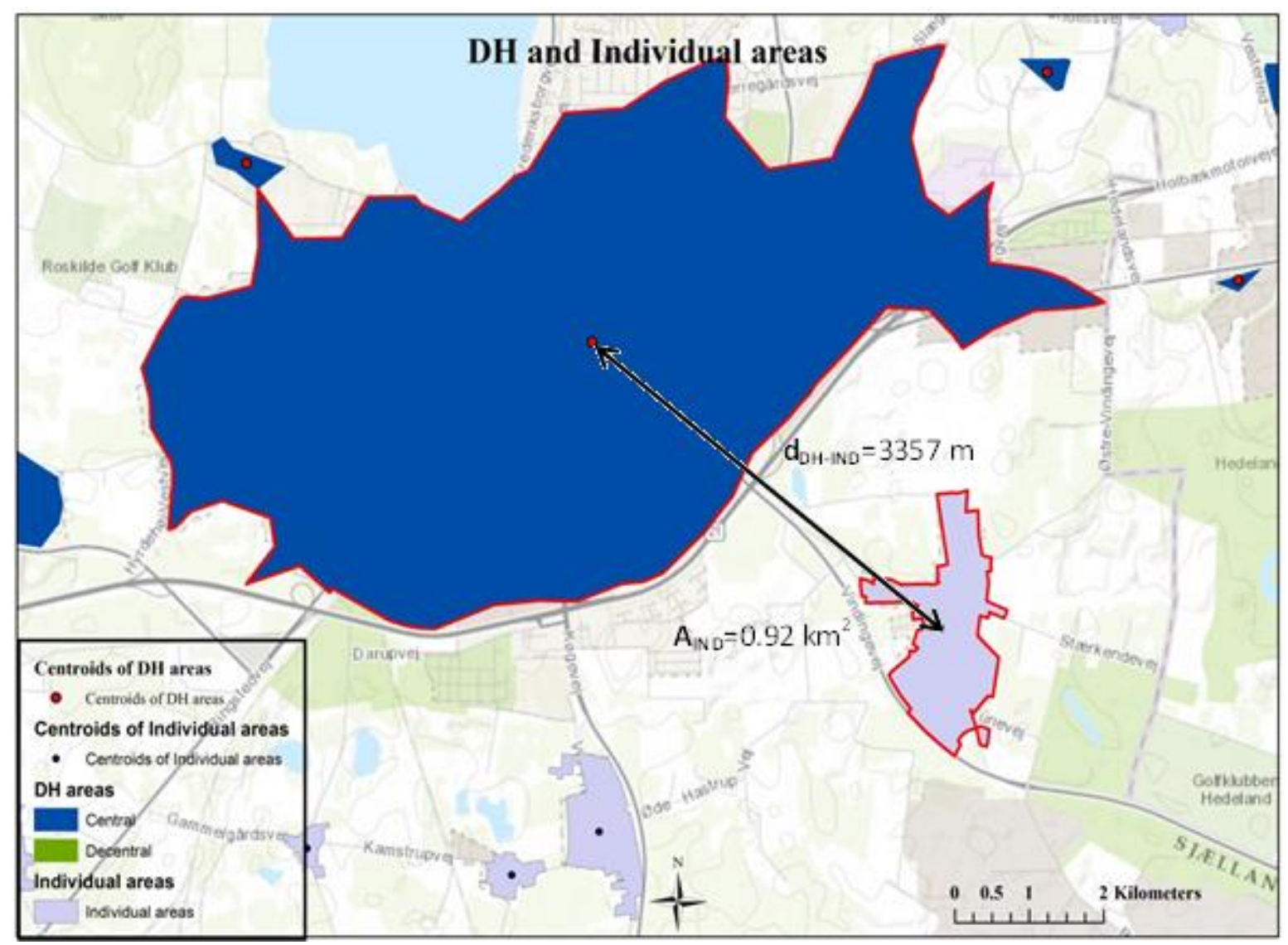

Figure 2. Process of measuring distance between DH and Individual area in Roskilde area.

Although applied approach clearly defines geographical areas and costs of connecting them to $\mathrm{DH}$, there is still room for refinement of this method:

- Distances $d_{D H-I N D}$ are measured using Near tool in ArcGIS and represent straight line distances. As this length represents the length of the supposed transmission pipeline, it would be a good addition to introduce a coefficient greater than or equal to one that will be used for multiplying measured distances in order to include differences in the terrain that supposed pipeline will be passing through. The introduction of this coefficient won't bring many changes to results of this analysis as it will increase expenses of expansion of DH systems to Individual areas, which are already seen as least profitable group of areas.

- Results of this analysis provide costs of connecting all buildings inside one area to district heating. Finally, the decisions on whether to connect to district heating or not are the decisions of individual consumers, so it is possible that some of the buildings decide against connecting to DH. Based on the equation (1), cost of connecting single building within $\mathrm{DH}$ area to a DH grid doesn't depend on number 
of buildings that will connect. On the other hand, cost of connecting single building within Next-to-DH and Individual areas is greatly increased with the decrease in the total number of connecting buildings. The graph presented in Figure 3 represents this fact for Individual areas - if there are fewer buildings dividing the costs of transmission and distribution infrastructure, the bigger the average costs are for the buildings that are being connected. The building-level detail provided by heat atlas gives possibility to include each building separately in equation (1) and thus calculate connection costs per building for any combination of buildings within a certain area.

- Certain buildings are characterized as DH supplied, but on the map these appear as an "island" of DH users, usually as groups of 5 to 20 buildings. After projecting the plants from Energy Producers Count [35] on the map within ArcGIS, it has been noted that there are no plant in a close vicinity of these buildings. It is likely that these buildings are supplied by "Blokvarme", small engines usually placed within one of the buildings. In reality it is not possible to connect to these in the same way as to other DH systems. The solution could be to identify and group these areas into group separated from DH areas and thus forbid ArcGIS software to measure distance to these areas. Due to current lack of valid data, this effect is left for further examination. 


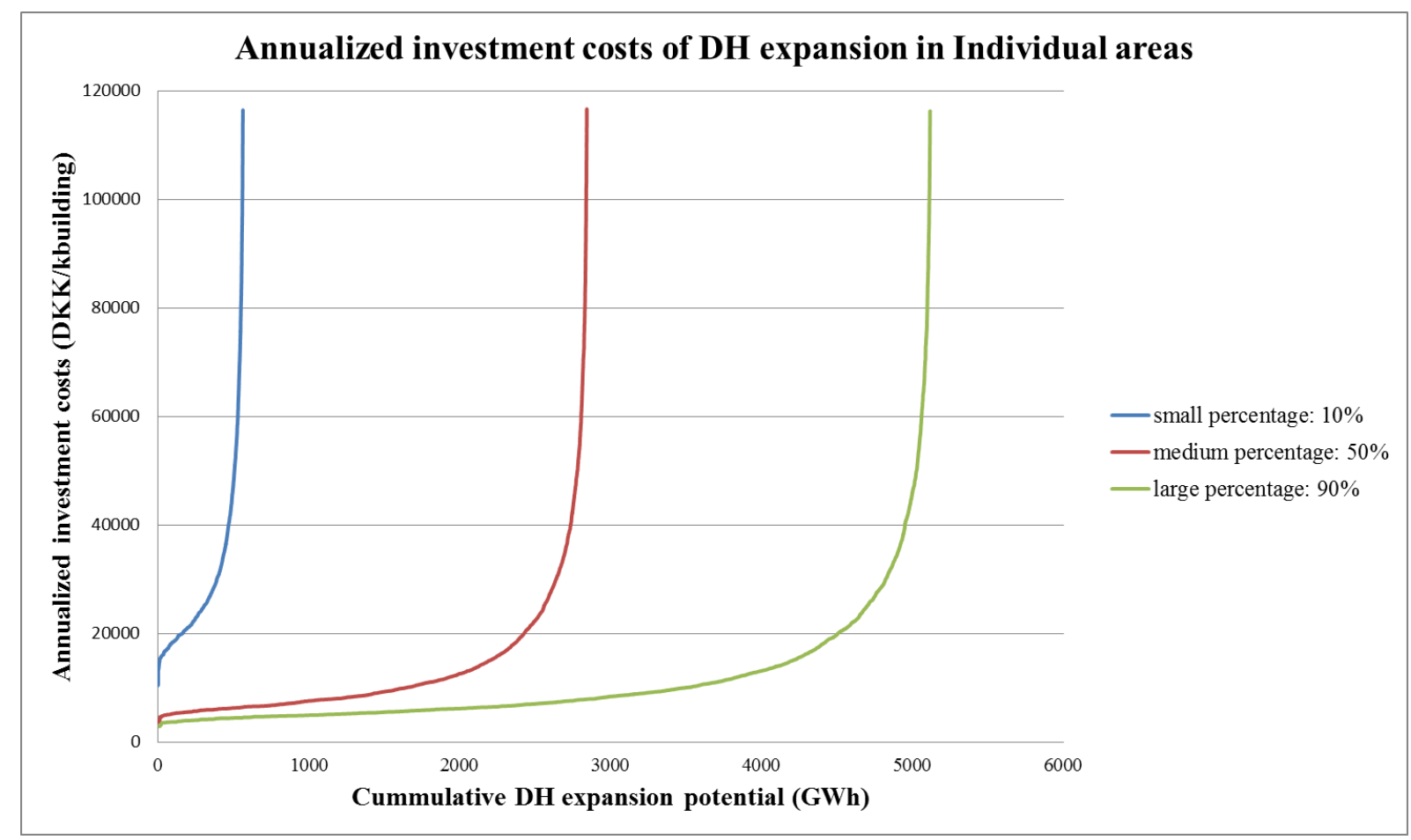

Figure 3. Annualized investment costs for different shares of buildings within Individual areas connecting to district heating.

\subsection{Marginal costs of heat saving measures}

The results of calculation of cumulative heat saving potentials and additional and full marginal costs for Denmark are presented in Figures 4 and 5. The curves that are showing potentials and costs of insulating hot water pipes can't be seen on the graphs due to small technical potential, even though costs are moderate. The installation of solar heating systems on the roofs seems as a solution with higher technical potential. If heat saving potentials and costs aren't disaggregated by heat saving technology, curves in Figure 6 are obtained. Costs are called additional marginal because they are additional and marginal: they are expressing additional costs of heat savings while scheduled maintenance is taking place, while in the same time denoting price of additional saved $\mathrm{kWh}$. 


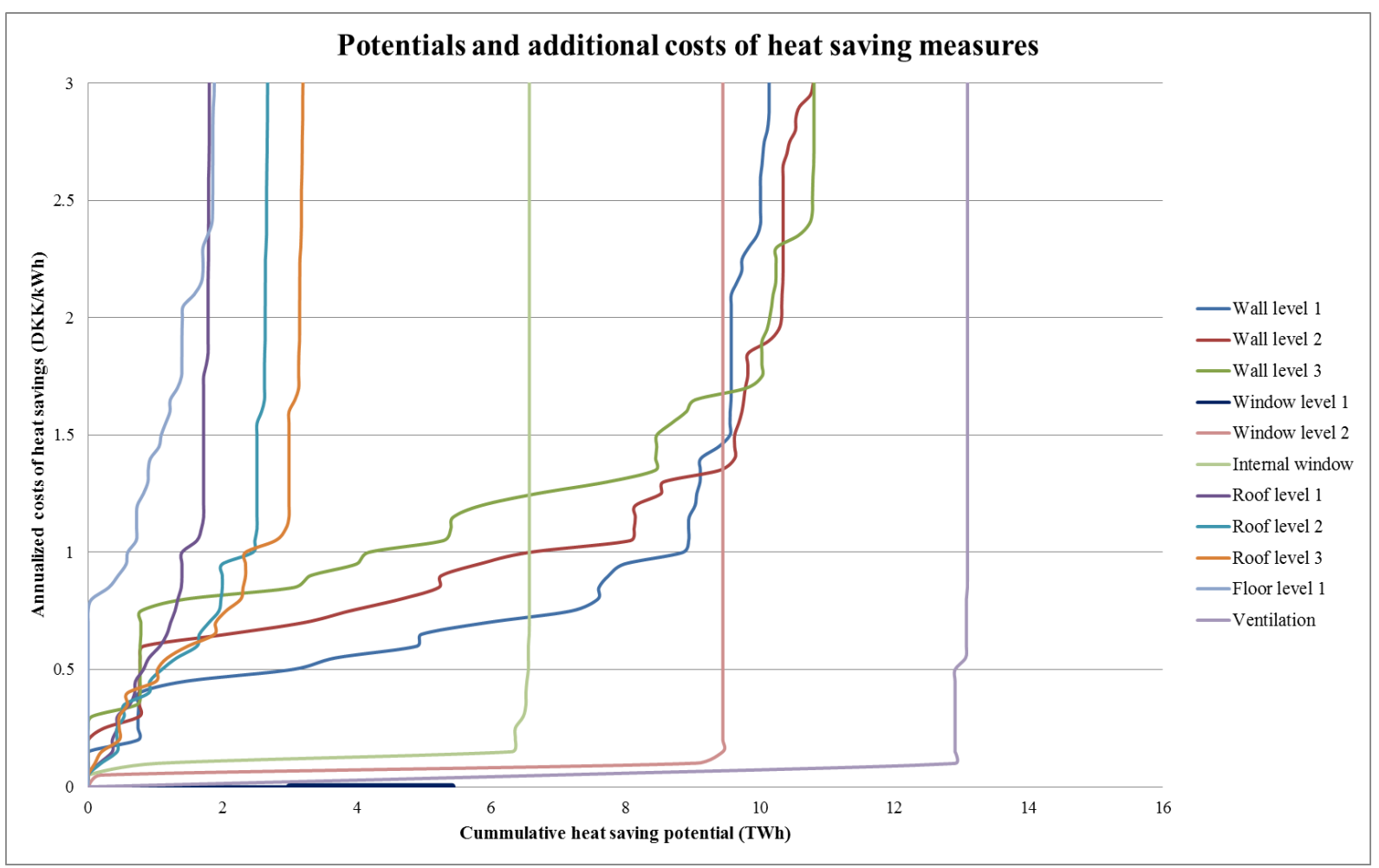

Figure 4. Cumulative potentials and annualized additional costs of heat saving measures.

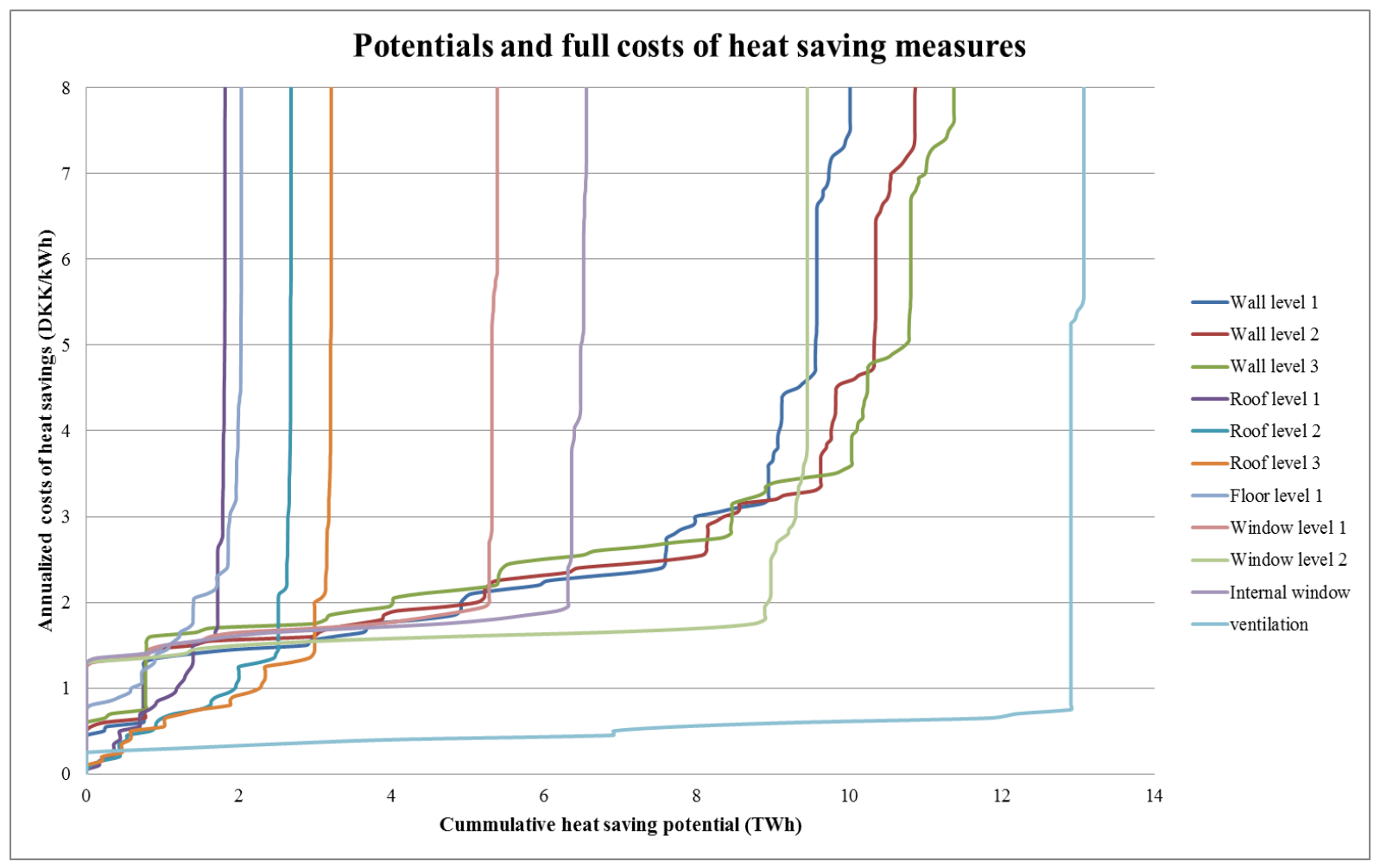

Figure 5. Cumulative potentials and annualized full costs of heat saving measures. 


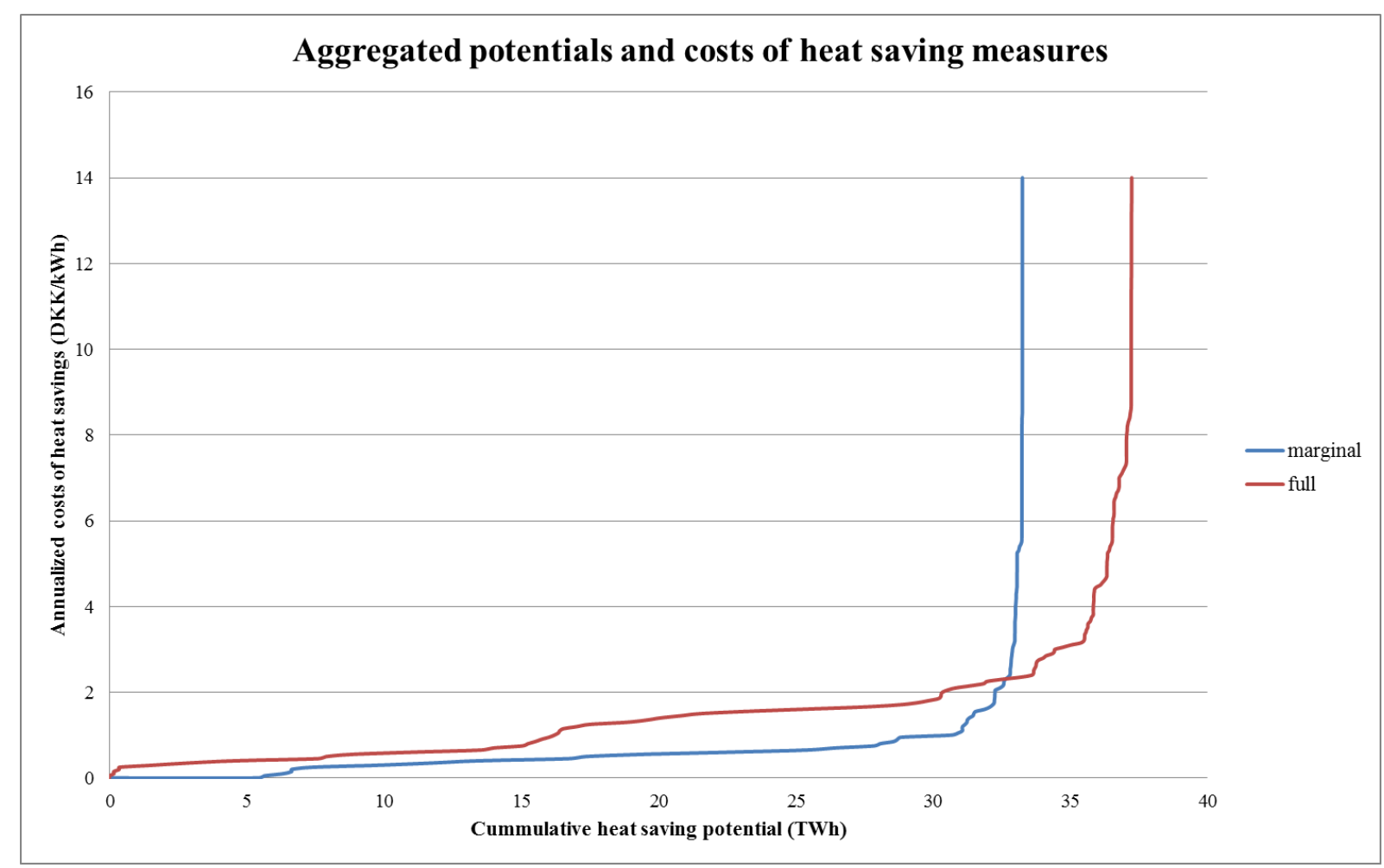

Figure 6. Cumulative potentials and annualized additional costs of heat saving measures without grouping by heat saving technology.

The highly-detailed and data-intensive spatial database, which serves as the foundation for heat atlas, is considered crucial for calculations of potentials for heat savings and associated costs. A heat atlas contains, among others, information about buildings' spatial coordinates, age, heated area and building type. These informations are used in the following way:

- Buildings' type is used to divide buildings into 5 type-groups: farmhouses, multistorey, detached, non-detached, and public/office buildings.

- Buildings' construction year is used to group buildings into 9 age-groups.

- 8 temperature regions as defined in [28].

- Each building had a value for $u_{\text {elem }}{ }^{\text {old }}, f_{\text {elem }}$ and $n\left(h^{-1}\right)$ assigned depending on which type and age group specific building is belonging to; these variables were mentioned in equations (3) and (4).

- Heated area of buildings, $A\left(m^{2}\right)$, is used directly for calculating heat saving in equations (3) and (4).

- A number of factors used for calculating $H_{\text {sol }}$ and $H_{\text {int }}$ had their values assigned according to membership to one of age or type groups. 
- Coordinates of buildings are used for visualising of results; as an example, Figure 7 shows buildings at Sealand that have at least one heat measure with annualized full costs lower than $0.1 \mathrm{DKK} / \mathrm{kWh}$. 


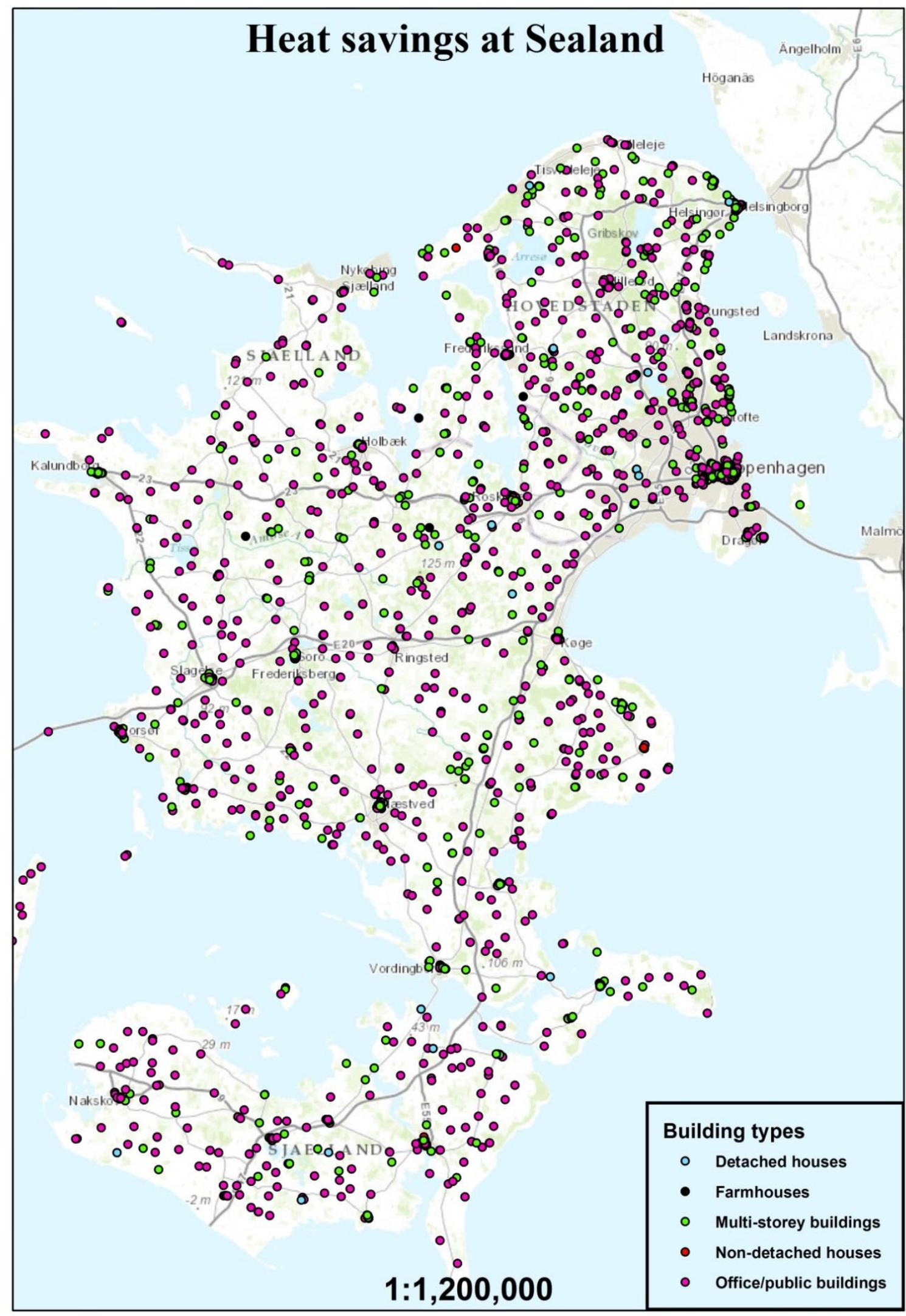

Figure 7. Use of heat atlas for representing results. Buildings with at least one heat measure with full annualized costs lower than $0.1 \frac{D K K}{k W h}$ are shown. 
Curves presented in Figures 3 and 4 represent good addition to heat atlas and can serve as a good approximation for wider geographical region or whole Denmark or as a first estimate for smaller geographical region. However, these costs are calculated from a system perspective and annualized using $4 \%$ socio-economic interest rate, which could be a problem in some cases. It is likely that in buildings with high u-values, where significant heat savings could be achieved, it is not feasible from private economic perspective. Buildings with high $\mathrm{u}$ values have poor energy standards, what is usually related to low property values. Further on, the low property values are usually related to low income of building's inhabitants, which makes investments in heat savings impossible, even though they are socio-economically costeffective. To confirm or disprove this relation between possibility for heat savings, property value and earnings of its inhabitants, data about later two would comprise valuable addition to Heat Atlas. It would be ideal for understanding of this phenomenon to analyse the data on single building level, but privacy issues could comprise a firm obstacle in getting access to these data. However, data averaged inside $1 \mathrm{~km}$ square would also make valuable addition to further research without compromising privacy of inhabitants, even inside areas with low population density.

The ownership of buildings is also one of social parameters that should be included in Heat Atlas, as it could possibly become a substantial barrier in achieving significant energy savings. For example, if heat prices are to be elevated in order to promote heat savings, this will usually be passed over to tenants, without efficiency improvements and reduced environmental impacts. Policy makers would greatly benefit from such addition, as this would give them an opportunity to explore spatial aspects of their policies; as an example, it would be possible to analyse whether to promote (or not to promote) loans with lower interest rates for installing energy efficient windows for multi-storey buildings built before 1973 where over $95 \%$ of inhabitants are also owners of apartments in certain area in Denmark.

\section{Discussion}

\subsection{Heat atlas as basis for energy system models}

Highly detailed database of physical building characteristics contained in heat atlas comprises a solid foundation for calculating heat demand and possible heat savings, as shown in Sections 2.2.3 and 3.2. The location of each building relative to the heat supply technologies could be used for the assessment of heat supply strategies by potentials, costs and 
environmental consequences. Thus, a heat atlas can be used as a tool for distinguishing between theoretical, technical, purely economical and economical potential when environmental and political constraints are taken into account. It can be used to represent increasing costs of utilising next portion of energy, the marginal costs, as presented in Figures 4, 5 and 6. These curves are continuous; they have no breaks, seen both from mathematical and geographical point of view. Mathematical continuity means that function describing costs has no breaks and gives costs for any valid value of cumulative heat saving potential, while geographical continuity implies that there are no "wholes" in representing space. In the other words, geographical continuity implies that each point on the cumulative cost curve has its spatial origin and vice versa. This fact also reflects important geographical aspect of renewable energy systems: energy resources, demand and supply are geographically distributed - this is the reason why spatially continual model is needed to mark the parts of these resources by technical, environmental and economic constraints.

Important property of heat atlas that goes hand-in-hand with calculating marginal cost curves is use of heat atlas' outputs as inputs to energy system analysis models. Beside the costs, heat atlas is also capable of delivering information to energy system analysis models about amount of available resources and impacts of used energy technologies.

Energy system analysis models can be seen as computer tools for exploring scenarios, preferably renewable energy scenarios. For the given inputs, such as current consumption and export/import of electricity and heat, projections of the future consumption and associated costs, amount of available resources and similar, models optimize energy systems by finding the best "mix" of technologies to satisfy demand for each discrete time step during the given period, taking availability and costs of resources into account. The optimizing is done by minimizing the sum of operation and investment costs or maximizing social welfare, while satisfying all the technical and non-technical constraints. The technical constraints ensure that power system works with high levels of safety and reliability. The best example of non technical constraint is Danish goal of being fossil fuel free apart from transport sector by 2035 - even though coal power plant could be the least costly technology to invest in 2035 even when taxes on coal are taken into account and there is still enough resources, models won't base their future energy supply on coal, because it's use is constrained in the model. 


\subsection{Heat atlas and energy models in recent studies}

There are two main types of energy system analysis models used in Denmark in recent years: optimization and simulation models. For the given curves that describe the marginal costs of utilising certain technology, optimization models are finding the "optimal mix" for each period within the analysed time frame. Simulation models depend on the experts' best guesses about which technology will be used in the future and in what amount. As an example, an input to an optimization model could contain marginal costs of utilising a solar resource by installing PVs, along with investment, operation and maintenance and fuel costs of competing technologies and amount of available resources. In this case, model will decide how big part of solar resource should be utilised from the socio-economic point of view. On the other hand, utilisation of solar resource will be given as input to simulation energy system models; in other words, experience and vision of experts making the analysis with these models are substituting for optimisation procedure in optimisation models. This claim can be well observed by looking at main representatives of two types of models used in Denmark when identical task is put in front of them - discover role of district heating in future Danish renewable energy system. Balmorel [36], as a representative of optimisation energy system models is used in [24], while EnergyPlan [37] was used in [20]. Both of the approaches agree that thorough energy system analysis is needed to discover optimal role of district heating in future renewable energy system, even though they are exploring different time frames - years 2025 and 2060, respectively. In both of the papers, heat atlas was used to identify potential scenarios and associated costs of expanding DH, while energy system analysis tools are used for modelling current and future Danish energy system. The main difference between the two approaches is that optimization model Balmorel chooses investment strategies in order to minimize the sum of operation and investment costs, while in simulation model Energy PLAN investments are fed in as exogenous inputs; 10 different heating technologies were compared. This is the reason why outputs from Balmorel can claim optimality, while EnergyPLAN's outputs rely on experts' vision of future energy system and can only claim to be a proper framework for analysing whether current opinions about district heating will be accurate in the future. Despite differences, results from both models conclude that gradual expansion of district heating in areas with high heat density, heat pumps in low density areas along with heat savings in buildings are an important components of future energy system.

Visualizing the outputs from energy system analysis models could be seen as another major benefit of a GIS-based heat atlas. The inputs into previously mentioned energy system model 
Balmorel are capacities of existing electricity and heat generation units, electrical power transmission capacities, heat and electricity demand, accompanied with fuel prices, $\mathrm{CO}_{2}$ costs, policies and taxes. Main outputs are productions, transmissions and demands for electricity and heat, fuels used and emissions. Both heat and power sector are geographically referenced. Heat sector is divided both by geographical location and technology used to produce heat. Information about which buildings are connected to district heating grids and their heat demand is also contained in heat atlas; registered production from heat plants and the district heating grid that the heat is delivered to are contained in [26]. The analysis of the spatial distribution of heat power plants and their annual production led to the conclusion which building is supplied from which heat power plant. Later, the unique relation between district heating grid and geographically referenced heating areas is used to place each building within one district heating area (Balmorel area). Geographical appearance of district heating areas in Balmorel is shown in Figure 8. Due to high number of areas, only areas in East Denmark are presented. When outputs from the model are calculated, it is possible to present them in a geographical manner.

\subsection{Use of Danish heat atlas in TIMES model for Denmark}

TIMES (The Integrated MARKAL-EFOM System) is an optimisation model generator for exploring energy scenarios. The model maximizes social welfare in society by maximizing the total surplus of producers and consumers over long time period using linear programming methods. Exploring the long-term energy scenarios is of special importance for Denmark due goal of being fossil fuel free society in year 2050. Different constraints can be defined in the model, such as amount and costs of available energy resources, workforce available in society, technical constraints for production, distribution and transmission technologies, demand, environmental and lifetime constraints, etc. The technological nature of the TIMES model and its economic foundation and properties are described in [38]. The detailed formulation of equations in TIMES is presented in [39]. 


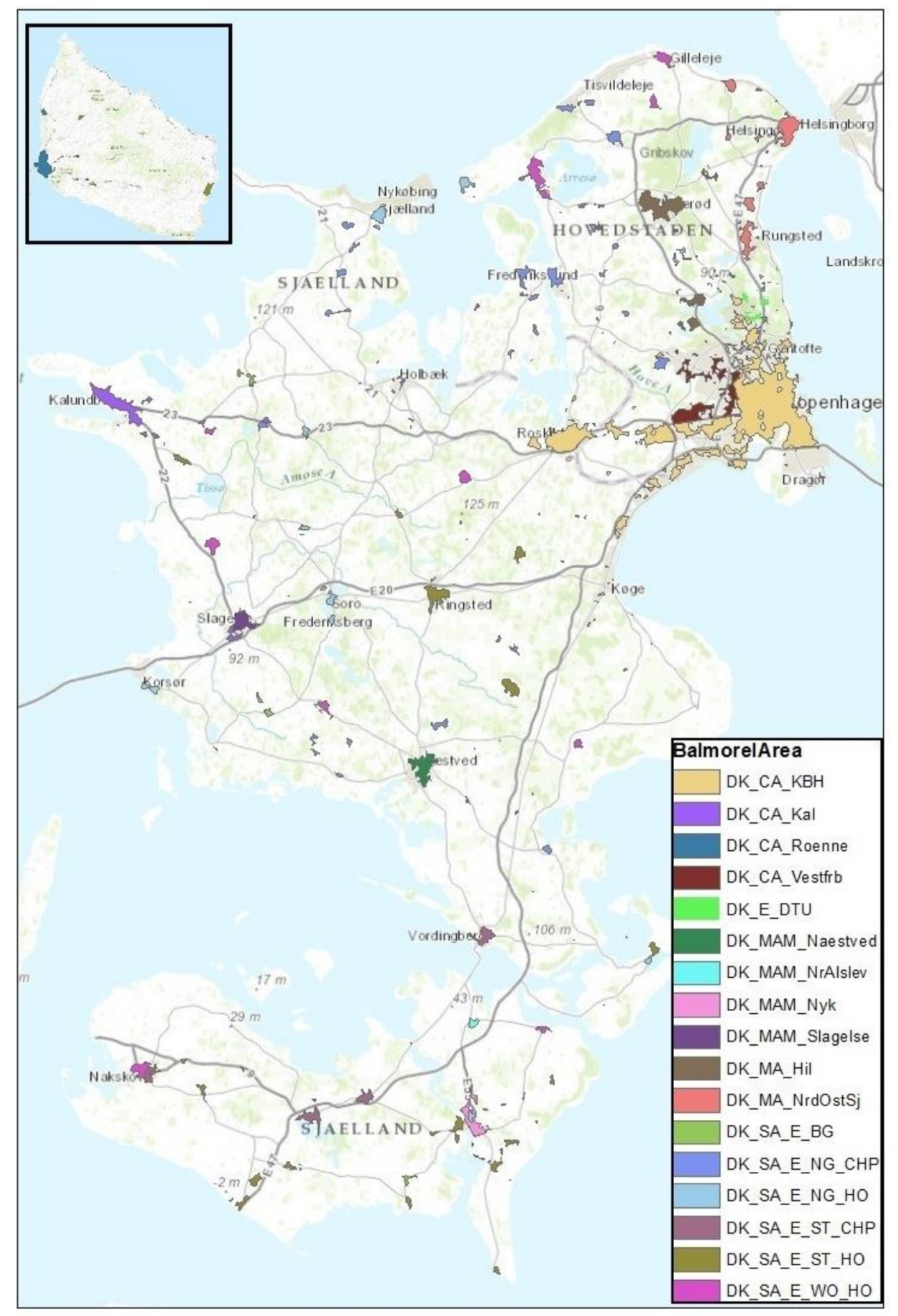

Figure 8. District heating areas in East Denmark suitable for representing results from Balmorel.

TIMES model for Denmark was created at DTU Management Engineering. Calculations of potentials and costs for heat savings and district heating expansion presented in Section 3.1 and 3.2 have been included in the model. District heating and heat savings in building stock have been defined as a heat generating technologies, which are competing in the model against individual heating technologies (gas and oil fired boilers, electrical heating, etc.). The conceptual idea is that the model is left to decide about optimal investment and operation strategy, when all limiting factors, such as future prices of fuels, availability of production technologies or emissions are taken into account. Similar approach regarding coupling of a 
heat atlas and TIMES model generator was observed in [40]. A detailed heat atlas with high spatial resolution was developed for the city of Salzburg and used for developing a roadmap for future energy infrastructure. The analysis of DH expansion and heat saving measures were important topics within this research.

All residential buildings in Denmark have been grouped according to their construction year (built before and after 1972), region (East and West Denmark), use (Detached and Multistorey) and position relative to district heating areas (Central, Decentral and Individual, as defined in Section 2.2.2). Multi-storey buildings include terrace houses and blocks of flats while Detached buildings include detached houses and farmhouses. In total, there are 24 different groups. For each of these groups, marginal and full cost curves of heat saving measures are created. These curves are approximated with 3-step curves of potentials (in MWh) and costs (in DKK/kWh) and imported into Household sector of TIMES model for Denmark. These approximations are presented in Figure 9 on the example of potentials and marginal costs of heat savings in Multi-storey buildings made before 1972 in Central areas in East Denmark. Model is also supplied with 12 2-step approximations of curves of DH expansion potentials and costs. 2-step instead of 3-step approximation is chosen because it is concluded from visual inspection that 2 -step curve gives sufficiently good approximation, as can be seen from Figure 10.

Since inputs and outputs from the TIMES model for Denmark don't have the same level of aggregation, it is not possible to directly input outputs from the model into a heat atlas. A disaggregation procedure for converting aggregated outputs from energy models into a heat atlas should be addressed within further research. Even in the aggregated form, results from energy system models can be spatially referenced and projected in GIS software or imported as separate layer into heat atlas. 


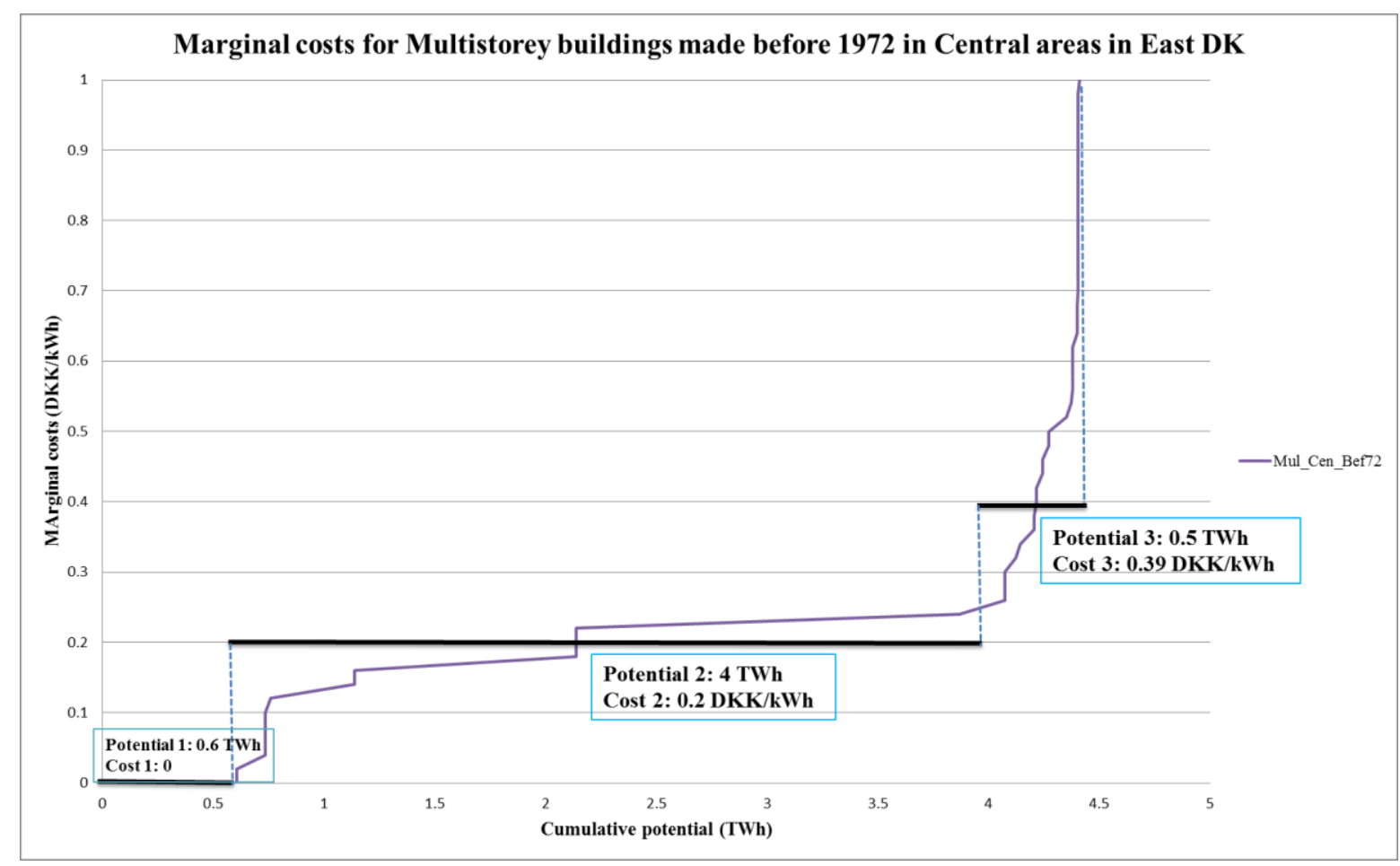

Figure 9. 3-step approximation of marginal cost curve of heat savings potentials and costs.

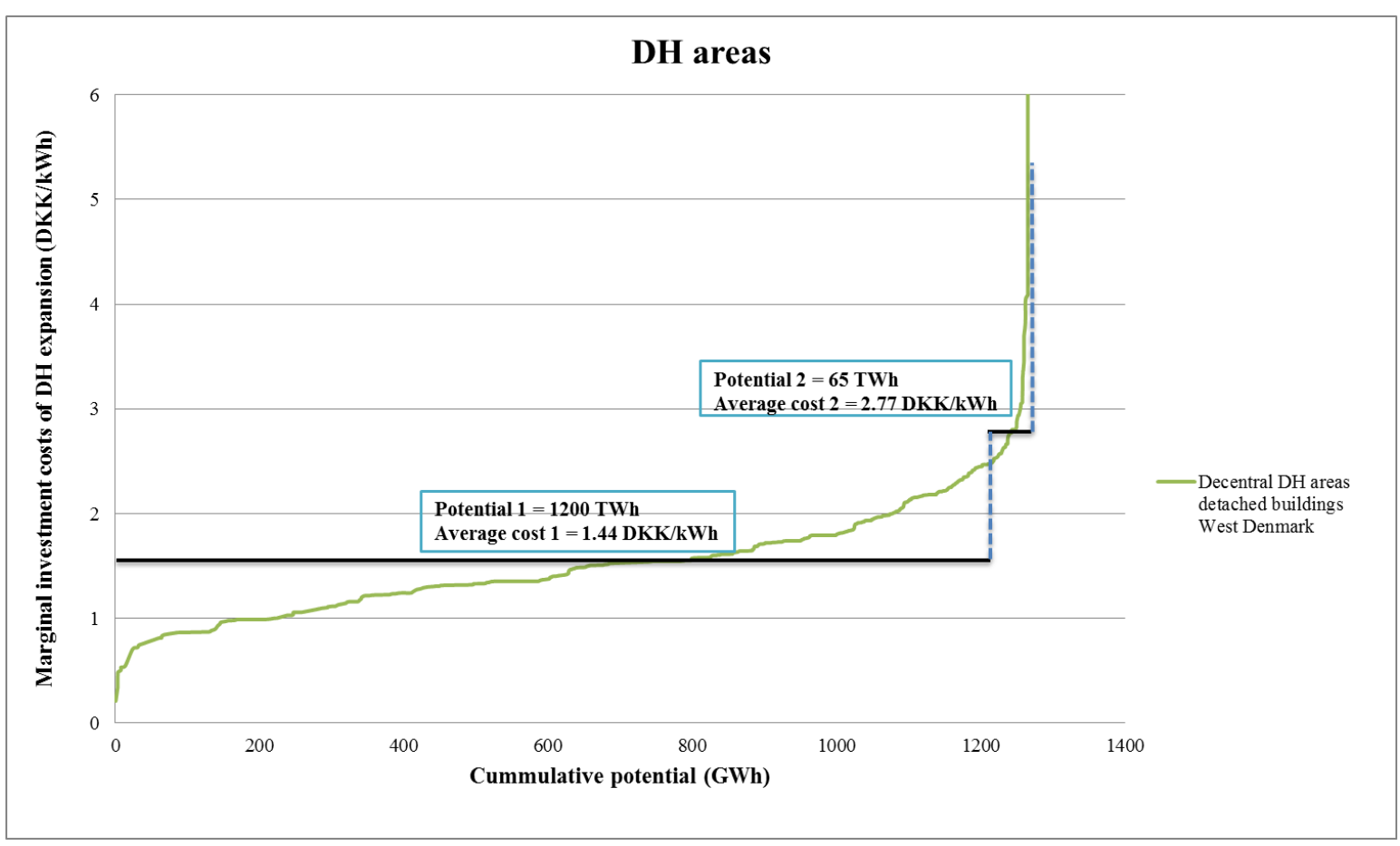

Figure 10. 2-step approximation of marginal cost curve of district heating potentials and costs. 


\subsection{Room for improvement of heat atlas}

A GIS-based heat atlas proved to be very useful tool for supporting planning of energy systems, especially in areas of heat savings in buildings and expansion of district heating systems. It contains large amount of spatially referenced data about building stock and population, which are part of extensive public registers that are being kept in Denmark. Measuring distances and densities and overlaying layers on top of each other are done with ease in heat atlas, while it is much more difficult to do it in any other way. Although it can serve well as a data container, heat atlas has possibilities for successful data retrieval and analysis. It works well with energy system analysis tools, by serving as a pre-analysis tool as well as for visually representing results. Despite all that, there is still room improvement of heat atlas - improving level of details of current data, improving models of heat savings and district heating expansion, adding new types of data and making automatic connection between heat atlas and energy models:

- More detailed values for $\mathrm{u}, \mathrm{f}$ and $\mathrm{t}^{\text {ind }}$ used in equation (3) depending on age, use, type of heating and geographical location instead of values representing national averages will give more accuracy to results.

- Adding social parameters, such as population age and density and type of building to empirical model will yield better representation of domestic hot water consumption; currently heat demand for DHW preparation is based on results from [37]. This approach serves as better approximation of energy consumption than the national averages, but it doesn't include behavioural aspects of DHW consumption.

- Data about measured heat demand would be a good addition to heat atlas and will eliminate any uncertainties with regard to accuracy of calculated heat demands, which match reality on national but not always on local level.

- Information about ownership, average income, property value, level of education would provide possibilities to investigate energy end-use and possibilities for analysis of heat saving investments on more detailed level.

- Detailed modelling of consumption of industrial consumers in heat atlas. The heat production of industrial producers is being recorded in the Energy Producers Count.

- Adding geographical data about solar, wind, biomass or geothermal resources, power, gas and electricity transmission lines and generation facilities would strengthen the role of heat atlas as data storage for energy system analysis models; this atlas would contain much more than just heat related data, so it could be called Energy Atlas. 
- Creating standard input and output forms in order to facilitate better communication (fully or partly automatic) between heat atlas (or energy atlas) and energy system modelling tools.

\section{Conclusions}

This paper addressed the use of a heat atlas for modelling of Danish energy system on its way towards $100 \%$ renewable energy future. First, transition of Danish energy system from inefficient imported oil-based to efficient renewable energy-based was put into historical context. Extensive use of CHPs and introduction of heat saving measures in the building stock have been identified as main contributors to the transition. The importance of continuous geographical mapping of demand and supply was denoted as important precondition for energy planning on municipal level. The development of heat atlases from paper based maps to modern GIS-integrated software tool was described. This paper then gave detailed description of heat atlas developed at Aalborg University, its functionality and contained elements. The expansion of district heating systems and heat saving measures in building stock have been presented as competing technologies that will both be present in future renewable energy system. Emphasis is put on spatially explicit analyses that produce cumulative potentials and marginal costs as output from the analysis. Examples of marginal costs calculations are shown for entire Denmark and put within general idea of this paper. Analytical models used for these calculations were presented in compact form, while underlining high level of detail provided by heat atlas. The use of heat atlas with energy system analysis tools was investigated and it was concluded that it can serve in multiple roles - as data-container, pre-analysis tool or as tool for spatially presenting results from analysis. Similarities and distinctions between simulation and optimization energy system models were underlined based on two studies of district heating expansion; heat atlas was extensively used for spatial analysis in both studies. Finally, it has been discussed how heat atlas could be improved - how heat saving model in heat atlas can be expanded and refined, current data made more detailed, new thematic layers added and connection with energy models established.

To conclude, heat atlas for Denmark has proven to be useful tool for strategic energy planning on national, regional and local level. Although it can serve multiple roles, strategic energy planning can't be based solely on heat atlas. In order to fulfil all aspects of energy 
planning, such as economic, environmental, energy and temporal aspects, heat atlas is often paired with energy system analysis tools. Joint analyses of this type give the possibility of perceiving future Danish energy system in the light of taken actions. Outputs from these analyses are providing answers to fundamental questions of the kind "What will happen to our energy system if these actions are undertaken?" and "What actions to take to achieve optimal energy system?".

\section{Acknowledgments}

The work presented in this paper is a result of the research activities of the Strategic Research Centre for 4th Generation District Heating (4DH), which has received funding from The Danish Council for Strategic Research.

The authors would like to thank Bernd Möller from Aalborg University for discussions about the spatial aspects of energy planning in Denmark.

\section{References}

[1]Danish Energy Agency. Energy Statistics 2012. <www.ens.dk/sites/ens.dk/files/info/talkort/statistik-noegletal/aarlig-energistatistik/tab2012.xlsx>; 2013 [accessed 25.04.14] [in Danish].

[2]Lund H. Renewable energy systems: the choice and modeling of $100 \%$ renewable solutions. Burlington, USA: Elsevier; 2010.

[3] Wall G. Conditions and tools in the design of energy conversion and management systems of a sustainable society. Energy Conversion and Management 2002;43(9-12):1235-48.

[4] Rezaie B, Dincer I, Esmailzadeh E. Energy options for residential buildings assessment. Energy Conversion and Management 2013;65:637-46.

[5]Möller B. A heat atlas for demand and supply management in Denmark. Management of Environmental Quality 2008;19(4):467-79.

[6] Moller B, Lund H. Conversion of individual natural gas to district heating: Geographical studies of supply costs and consequences for the Danish energy system. Applied Energy 2010;87(6):1846-57.

[7] Lund H, Andersen A. Optimal designs of small CHP plants in a market with fluctuating electricity prices. Energy Conversion and Management 2005;46(6):893-904. 
[8]Genon G, Torchio MF, Poggio A, Poggio M. Energy and environmental assessment of small district heating systems: Global and local effects in two case-studies. Energy Conversion and Management. 2009;50(3):522-9.

[9] European Commission. Directive 2009/28/EC of the European Parliament and of the Council of 23 April 2009 on the promotion of the use of energy from renewable sources and amending and subsequently repealing directives 2001/77/EC and 2003/30/EC. L 140/16. Official Journal of the European Union 2009.

[10] Aydin NY, Kentel E, Duzgun HS. GIS-based site selection methodology for hybrid renewable energy systems: A case study from western Turkey. Energy Conversion and Management 2013;70:90-106.

[11] Finney KN, Sharifi VN, Swithenbank J, Nolan A, White S, Ogden S. Developments to an existing city-wide district energy network - Part I: Identification of potential expansions using heat mapping. Energy Conversion and Management 2012;62:165-75.

[12] Finney KN, Chen Q, Sharifi VN, Swithenbank J, Nolan A, White S, et al. Developments to an existing city-wide district energy network: Part II - Analysis of environmental and economic impacts. Energy Conversion and Management 2012;62:176-84.

[13] Christensen BA, Jensen-Butler C. Energy and urban structure: Heat planning in Denmark. Progress in Planning 1982;18:57-132.

[14] Wittchen KB. Assessment of the heat saving potential in existing buildings. Danish Building Research Institute. < http://www.sbi.dk/miljo-og-energi/energibesparelser/energibesparelser-ieksisterende-bygninger/vurdering-af-potentialet-for-varmebesparelser-i-eksisterende-boliger >; 2004 [accessed 25.04.14] [in Danish].

[15] Karlsson K, Næraa R. Heat loss from Buildings: Determination of heat loss coefficients for buildings in Denmark for SESAM computations. Lyngby: Department for Buildings and Energy, Technical University of Denmark; 1998 [in Danish].

[16] Rambøll Denmark A/S, Aalborg University. Heat plan Denmark, Appendix. <http://vbn.aau.dk/files/16591726/ Varmeplan_bilagsrapport.pdf>; 2008 [accessed 25.04.14] [in Danish].

[17] Petrovic S, Karlsson K. Model for Determining Geographical Distribution of Heat Saving Potentials in Danish Building Stock. ISPRS International Journal of Geo-Information 2014;3(1):143-65.

[18] Persson U, Werner S. Heat distribution and the future competitiveness of district heating. Applied Energy 2011;88(3):568-76. 
[19] Lund H, Moller B, Mathiesen BV, Dyrelund A. The role of district heating in future renewable energy systems. Energy 2010;35(3):1381-90.

[20] Hedegaard K, Münster M. Influence of individual heat pumps on wind power integration Energy system investments and operation. Energy Conversion and Management 2013;75:67384.

[21] Sperling K, Moller B. End-use energy savings and district heating expansion in a local renewable energy system - A short-term perspective. Applied Energy 2012;92:831-42.

[22] Nielsen S, Moller B. Excess heat production of future net zero energy buildings within district heating areas in Denmark. Energy 2012;48(1):23-31.

[23] Tommerup H, Svendsen S. Energy savings in Danish residential building stock. Energy and Buildings 2006;38(6):618-26.

[24] Münster M, Morthorst PE, Larsen HV, Bregnbæk L, Werling J, Lindboe HH, et al. The role of district heating in the future Danish energy system. Energy 2012;48(1):47-55.

[25] Christensen K. Calculation of gross energy. Simplified calculation. Teaching Notes. Technical University of Denmark; 2004 [In Danish].

[26] Wittchen KB, Kragh J. Danish building typologies. Participation in the TABULA project. Danish Building Research Institute. <http://www.sbi.dk/miljo-ogenergi/energibesparelser/danish-building-typologies-participation-in-the-tabula-project/danishbuilding-typologies>; 2012 [accessed on 25.04.14] [in Danish].

[27] Kragh J, Wittchen K B. Energy demand of Danish buildings in 2050. Danish Building Research Institute. <http://www.sbi.dk/miljo-og-energi/energibesparelser/danske-bygningersenergibehov-i-2050/danske-bygningers-energibehov-i-2050>; 2010 [accessed on 25.04.14] [in Danish].

[28] Wang PW. Reference Values: Daily, monthly and yearly values for temperature, relative humidity, wind speed, global radiation and precipitation for regions and the whole country Denmark in period 2001 - 2010. Danish Meteorological Institute < http://www.dmi.dk/fileadmin/Rapporter/TR/tr12-22.pdf>; 2013 [accessed on 25.04.2014.]

[29] Zvingilaite E. Health Externalities and Heat savings in Energy System Modelling. PhD Thesis. DTU Management Engineering, Technical University of Denmark, Kgs. Lyngby, Denmark; 2012.

[30] Tommerup H, Laustsen JB. Energy savings in public sector buildings. Technical University of Denmark, DTU BYG, Kgs. Lyngby, Denmark; 2008 [In Danish]. 
[31] Bøhm B, Schrøder F, Bergsøe NC. Domestic hot water. Measurements of consumption and heat losses from circulation lines. Danish Building Research Institute. < http://vbn.aau.dk/files/17689984/sbi_2009-10.pdf >; 2009 [accessed on 25.04.14] [In Danish].

[32] Tommerup H. Energy Renovation measures - catalogue. Technical University of Denmark, DTU BYG, Kgs. Lyngby, Denmark; 2010 [In Danish].

[33] Danish Energy Agency. Updated sheet on discount rates, lifetime and reference for Guidelines for socio-economic analyzes of energy from April 2005 (Calculation examples revised July 2007). <http://www.ens.dk/sites/ens.dk/files/info/talkort/fremskrivninger-analyser-modeller/samfundsoekonomiskeanalysemetoder/notat_om_kalkulationsrenten_juni_2013.pdf>; 2013 [accessed on 25.04.14] [in Danish].

[34] Energinet.dk, Danish Energy Agency. Individual Heating Plants and Energy Transport Technology data for energy plants. < http://www.ens.dk/sites/ens.dk/files/dokumenter/publikationer/downloads/technology_data_for _individual_heating_plants_and_energy_transport.pdf>; 2012 [accessed 25.04.14].

[35] Danish Energy Agency. Energy Producers count; 2012 [In Danish].

[36] Ravn H. The Balmorel Model Structure. Ravn H. The Balmorel Model Structure. <http://www.balmorel.com>; 2011 [accessed 25.04.14].

[37] Aalborg University. EnergyPLAN: Advanced Energy System Analysis Computer Model. < http://www.energyplan.eu/> [accessed on 25.04.14].

[38] Labriet M, Loulou R. ETSAP-TIAM: The TIMES integrated assessment model Part I: Model structure. Computational Management Science 2008;5(1-2):7-40.

[39] Loulou R. ETSAP-TIAM: The TIMES integrated assessment model, part II: Mathematical formulation. Computational Management Science 2008;5(1-2):41-66.

[40] Reiter D, Botzenhart F, Mühlich P, Hamacher T, Reuter A. Developing a Roadmap for the Future Energy Infrastructure in Salzburg. In: Preceedings of IAEE, Salzburg, Austria; 2009. p. 1361-1366. 